\title{
Design and Implementation of Multi-function Protection for Distribution Transformer Connected to PV systems
}

\author{
Khairy Sayed ${ }^{1}$, Farid Naguib Abdelbar ${ }^{2}$, Emad Elzohri ${ }^{3}$, Amal Edwar ${ }^{3}$ \\ Faculty of Engineering, Sohag University, Sohag, Egypt ${ }^{1,2}$ \\ Faculty of Technology and Education, Sohag University, Sohag, Egypt ${ }^{3}$
}

\begin{abstract}
Residential rooftop-mounted solar photovoltaic (PV) panels are being installed at an increasing rate, worldwide. There have been concerns over possible issues such as overvoltage and overcurrent. These PV systems are mostly connected at low voltage (LV). This paper presents a way to protect transformers from any harmful change in current, voltage, frequency and high temperature. The experimental system consists of a step-down transformer, current sensor, temperature sensor, and ARDUINO MEGA to monitor and control the system. The operating values are monitored using PC. The model of the system is simulated using MATLAB/PROTEUS. The performance of the system is investigated at normal conditions as well as at faulty conditions. The system succeeds to disconnect the loads to protect the transformer and displaying the values on real time.
\end{abstract}

Keywords: Distribution transformer; Protection relay, Arduino-based, PV system.

\section{INTRODUCTION}

Small rooftop installations of SPV produce power in the kilowatt range, while large solar farms can generate several megawatts. In both cases, inverters are used for power conversion from DC to AC. SP sources in this class are usually connected to distribution systems. The use of inverters always causes voltage distortion and injects current harmonics into the system. In addition, connected SPV introduce additional sources on distribution system lines, which reduce power flow from traditional supplies and can cause reverse power flow [2-5]. The immediate effects of SP and their associated inverters would be on the distribution transformer, which is designed to supply linear loads at rated frequency. Voltage and current harmonics are expected to yield extra core and winding losses, and hence higher temperature rise. If the temperature at the transformer winding exceeds the normal value, insulation degradation will be possible leading to shortened lifetime and earlier breakdown of the transformer due to existing hottest-spot.

The study of harmonics in terms of sources, effects, filtration, and mitigation has been constantly attracting attention of electrical power system researchers. The effect of power system harmonics on the performance and lifetime of distribution transformers is addressed in many publications [5 - 10].

Voltage and current harmonics caused by various nonlinear lighting loads are presented in [8] and de-rating of the distribution transformer is accordingly proposed. In [13], the effect of solar panels and associated inverters on the power quality of distribution networks and transformers is investigated. Cases of unbalanced operation of distribution transformers are studied through simulation and experimentation.

Increasing the number of photovoltaic production units connected to the network has led to a need for examining the effects of the distribution system [14]-[15]. Photovoltaic systems can cause voltage fluctuations due to the changes on the solar energy. It also causes power factor problems due to active power changes in the system. In addition, as the photovoltaic systems were designed as unidirectional, protection plans are affected when the network operates in bidirectional power flow mode. Single-phase photovoltaic production due to unbalanced distribution system is a voltage imbalance between the phases [16-17].

The distribution transformer needs to be protected against any harmful change in voltage, current, frequency and temperature. If the loads increased, the transformer would be overloaded and that causes the current to be increased rapidly and the voltage decreased suddenly, that will cause in a transformer failure. If the transformer cooling process isn't working regularly, the transformer is overheated, and it also leads to transformer failure. Those failures are too dangerous for the transformer and too costly, so we are in a serious need for protection techniques. Poor quality of power supply may result into increased power losses, production loss, and power outages and causes undesirable behavior of equipment and may cause damage to the equipment connected to the LV side of the transformer. It economically affects the customers by damaging their appliances connected to the power source [18-26]. 
International Journal of Innovative Research in Electrical, Electronics, Instrumentation and Control Engineering

Vol. 9, Issue 3, March 2021

\section{DOI 10.17148/IJIREEICE.2021.9301}

In this paper, ARDUINO MEGA controller is used to control the system. ARDUINO is an electronic and open source board used to develop many projects through an open source programming language called ARDUINO C. The main controller is connected to sensors to perform a specific function like LM35 temperature sensor, current sensor, motion sensors and light sensors.... etc. it's also connected to a computer to monitor the temperature, current, voltage and frequency values. The AC signal passes through a transformer to decrease the voltage from 220 to 3 volts RMS. Then a diode is used to eliminate the negative portion of the signal. To measure the frequency, we introduce a simple code algorithm to calculate the time between two identical points on the signal. But first the signal had to be converted into a digital square wave to make the measurements accurate. The model of the system is simulated using MATLAB/PROTEUS. The objective of this paper is to provide a hardware test-bed that is constructed to investigate the performance of distribution transformer protection system in case of PV penetration. The protection functions are checked for the proposed system.

\section{Proposed System}

The aim of this study is to present a system for monitoring the voltage, current, temperature, and frequency to protect the distribution transformer from dysfunctional due to the overloading currents, high voltage spikes and over-heating of transformers oil. The system is based on Ardunio microcontroller that is very high speed and cost effective device with enhanced accuracy. Microcontroller based relays are more popular because of no mechanical operation, microcontroller sense the voltage, current, temperature, and frequency of the transformer continuously. As the value of current, voltage and frequency increases from pre-set values, protection scheme operates and trips the load. Likewise, as the temperature increases to a set value, a fan would be turned on for cooling the transformer. Thereafter regarding the monitoring and control, information about the operation of transformer parameters would be transmitted to a personal computer for general monitoring and control. The system can be installed at the distribution transformer and by measuring above parameters it will help the utilities to optimally utilize the transformers and identify problems [27-30]. The system is fixed on the secondary of the distribution transformer and the monitored output will be display on a PC connected to the system. The monitored output values are compared with the rated values of the transformer and the microcontroller is programmed in such a way that if the monitored values are exceeds a certain set value then the relay become active and cut the supply and thereby allows the transformer to free from faults such as over loading. The microcontroller continuously scans the transformer and updates the parameters to the display.

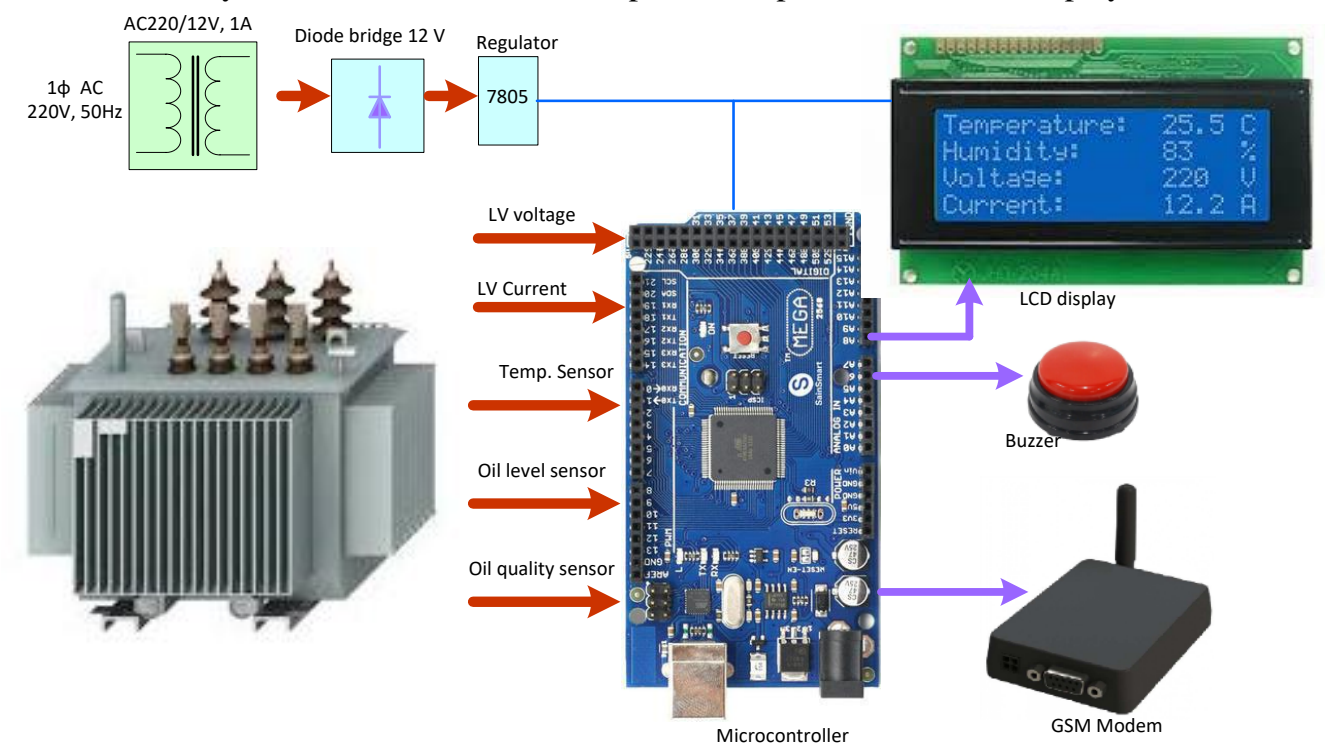

Fig. 1 Proposed protection system

\section{III.SYSTEM SIMULATION}

The whole electronic circuit is simulated using Proteus program as shown in Fig. 2. A reducing voltage transformer is used to convert the voltage from 220 volts RMS to 3 volts RMS, that's because the maximum value that the ARDUINO can afford is 5 volts PEAK, and then the signal is inserted to a DIODE to eliminate the negative portion of the AC signal. After that we use a circuit called "Transistor as a switch" to convert the analogue AC sine wave into digital signal to be measured by the ARDUINO. It's better to use a digital signal in the measurements than the analogue signal 
International Journal of Innovative Research in Electrical, Electronics, Instrumentation and Control Engineering

Vol. 9, Issue 3, March 2021

\section{DOI 10.17148/IJIREEICE.2021.9301}

because it's not affected by noise like the analogue one, and also the ARDUINO can measure it effectively. To measure the voltage we take the analogue signal after the DIODE to the analogue pin of the ARDUINO "A5". To measure the frequency, we take the digital signal after the "Transistor as a switch" circuit; it has the same frequency of the input AC signal. To measure the current, a current sensor is used and connected in serial with the loads. It's output is an analogue voltage increases from 0 to 5 volts respectively with current value, which is inserted to the analogue ARDUINO pin "A3".To measure the temperature, LM35 temperature sensor is used. That sensor has an output of 0 up to 5 volts, increases respectively with the surrounding temperature. It is inserted to the analogue ARDUINO pin "A8".Then we use three indicating LEDs, expressing any change of voltage, current, frequency respectively. A relay also is used in serial with the loads to disconnect them in case of any harmful change in voltage or frequency or current. In case of increase the temperature, a 12 volts DC fan is turned on to cool the transformer, it's driven by using the simple circuit of a transistor as a switch to transfer the effect of the 5 volts ARDUINO signal to the 12 volts fan. Our circuit's power came from a 12 volts DC adapter, which has a maximum of 2 amperes; the power is regulated by using " 2805 " regulator to make use of two DC volts powering the circuit: 12 volt to power the DC fan and 5 volts to power the Rest of the circuit.

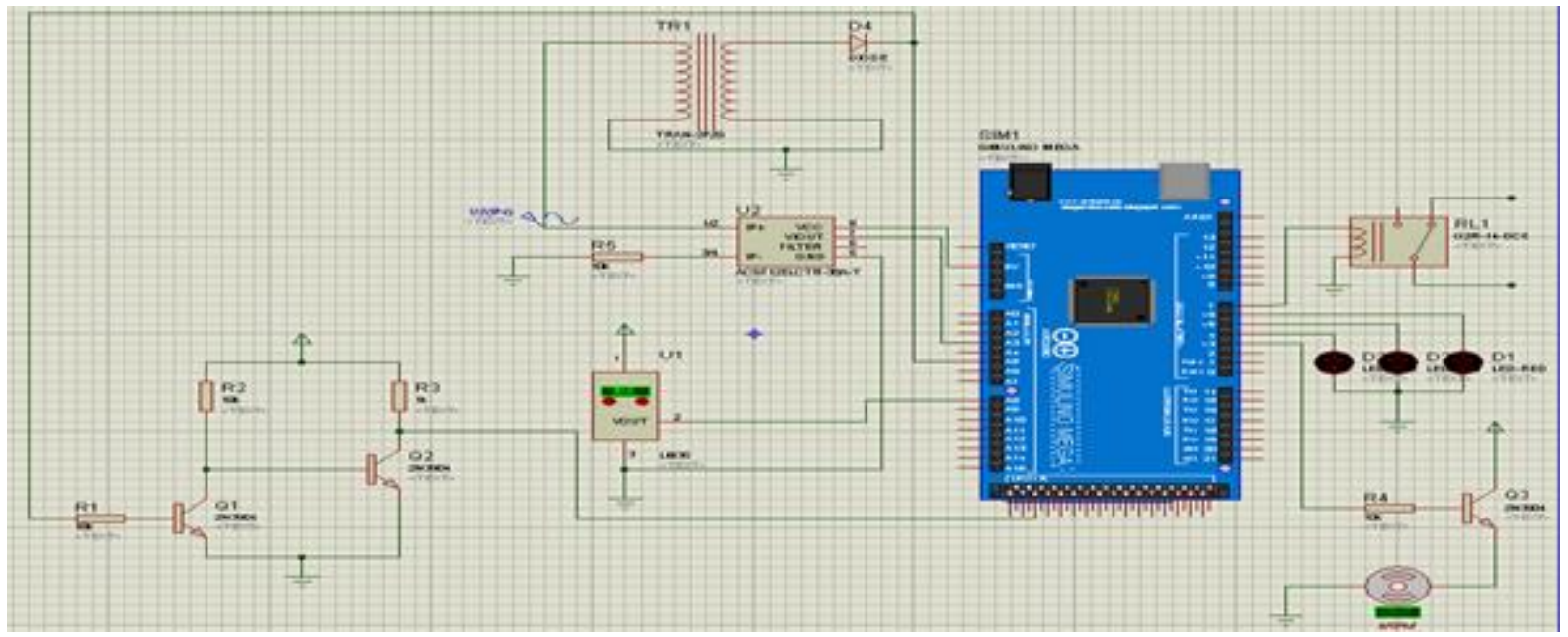

Fig.2 The entire electronic circuit simulation on PROTEUS

This circuit contains mainly of five individual circuits:

1. Frequency meter circuit.

2. $\quad$ Voltage meter circuit.

3. Temperature measurement circuit.

4. Current meter circuit.

5. Fan driving circuit.

A. Frequency meter circuit:

1. The general purpose from this circuit:

2. Convert the analog sine wave signal into a digital square wave signal with keeping the same frequency of the input signal. [7]

3. Eliminate the negative portion of the input signal, as the output is between + Vcc and zero.

\section{B. Voltage meter circuit:}

Definitely, the ARDUINO can't deal with the high power signal, so we used a (220:3) transformer to reduce the signal power down to 3 RMS volts.

Also since that the ARDUINO can't deal with the negative portion of the signal, so we used a diode as a half wave rectification to eliminate the negative portion.

\section{Temperature measurement circuit:}

By using LM35 datasheet, we define the (Vic, GND, output) pins of the sensor and then connect the output pin directly to the ARDUINO. Also, every 10 mille-volts express a change of only one degree Celsius.

This sensor has an output of 0 up to 5 volts, increases respectively with the surrounding temperature. It is inserted to the analog ARDUINO pin "A0". 
International Journal of Innovative Research in Electrical, Electronics, Instrumentation and Control Engineering

Vol. 9, Issue 3, March 2021

DOI 10.17148/IJIREEICE.2021.9301

\section{Current meter circuit:}

We use "ACS712-30A" current sensor to measure the output current from the transformer. This sensor can measure up to 30 amperes $\mathrm{AC}$, and has maximum output voltage of 5 volts This sensor has 3 DC pins (Vcc, output, GND), the output pin is the one which is connected to the analog ARDUINO pin. From the sensor datasheet, every 66 mille-volts express a change of only one ampere. [8]

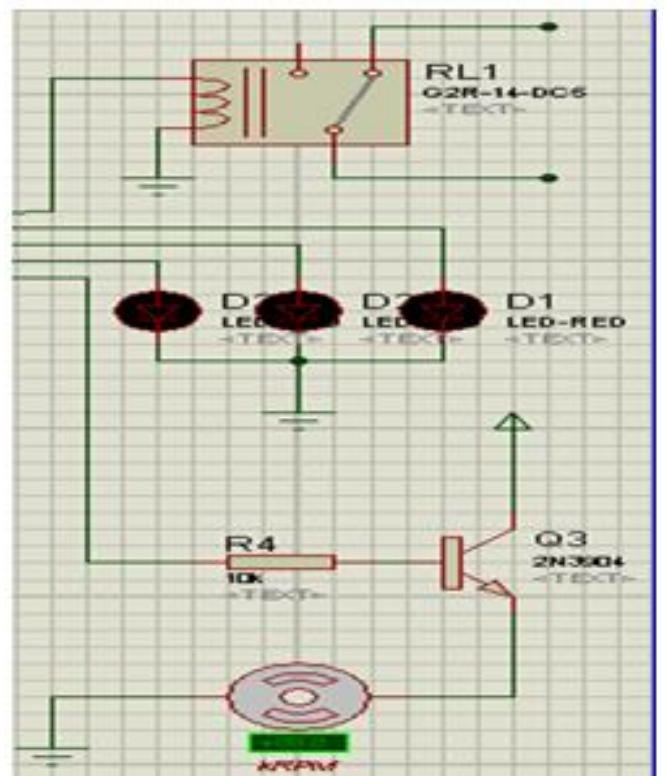

Fig. 3. Output circuits on PROTEUS

The outputs of controlling circuits are three circuits which control over the outputs of the ARDUINO, and they are:

1. A relay to disconnect the loads in case of any harmful change in voltage or current or frequency.

2. Three LEDs are indicating the change in voltage, current and frequency respectively.

Note: the LEDs we used are 3 volts LEDs and they are connected to a 5 volts source, so we need a small resistor for every LED acts as voltage divider.

3. A 12 volts DC fan runs in case of high temperature, and is driven by a transistor in order to be controlled by the 5 volts ARDUINO signal.

Note: here we use the transistor as a switch circuit to control the fan.

To provide the whole circuit with power, we use a 12 volts adapter, and " 2805 " regulator to get both 5 volts and 12 volts. [10]

\section{IV.CONTROL SCHEME}

If a parameter of any distribution transformer exceeds the predefined value/level, alerts will be received on the developed web application showing the particular transformer's location, to take necessary action. Commands of controlling transformer's operation can be issued from the web application itself. Selected advantages of this method are like, continuous monitoring of Distribution Transformer, timely alerts to rectify the abnormality if any, thereby extending the lifetime of distribution transformers, simplifying the troubleshooting in the distribution network and providing customers with proper service. The flow chart of protection and control scheme is shown in Fig. 4. Arduino programming through the following elements:

- $\quad$ Temperature measurement module.

- $\quad$ Current measurement module.

- $\quad$ Voltage measurement module.

- $\quad$ Frequency measurement module.

Software coding is done using Arduino Mega. The Microcontroller's coding is done on arduino IDE. IDE Driver is a program running on the computer that allows drawing a sketch in microcontroller. Arduino relies on C-language of programming. Atmega 2560 based Arduino mega is configured to gather readings from all sensors and upload them to 


\section{DOI 10.17148/IJIREEICE.2021.9301}

web server using Ethernet based internet connection. Microcontroller take readings and upload them at a regular interval of 15 seconds. Here, resistive load is used as a load to transformer.

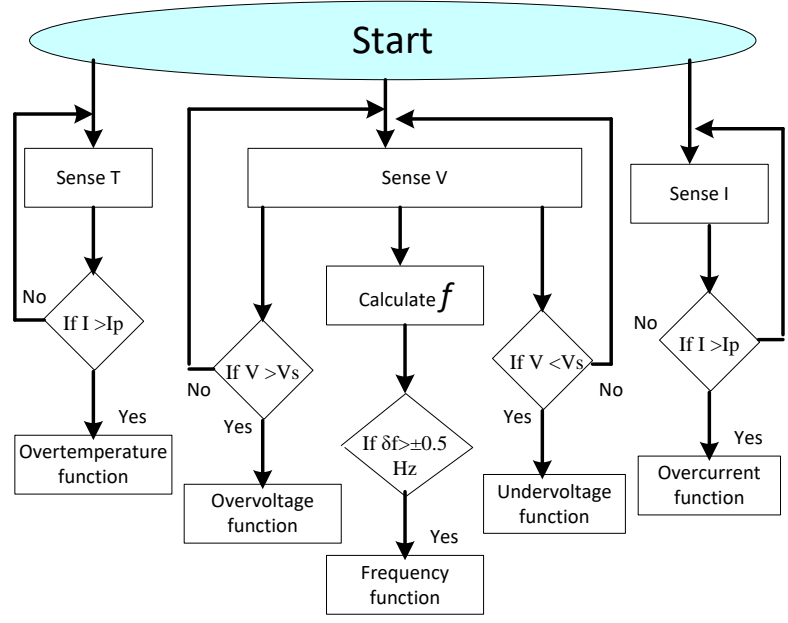

Fig. 4 Flowchart of the protection program

\section{A. Over-current protection}

For the over-current protection, the relay operates with or with-out an intended time delay and trips the associated circuit breakers when the current flowing into the relay exceeds a setpoint value.

The flow of over-current may have severe damage to both the faulty and healthy parts of power system [3].The principle of operation of the proposed MNR underover-current conditions is based on the IEEE Standard Inverse-Time Characteristic Equations for Over-current Relays, [7]. These equations express a relationship between the relay current and the time setting of the relay.

$$
t=\frac{K}{I^{n}}
$$

where I is the relay current, Ip is the pick-up current, $\mathrm{K}=$ constant and $\mathrm{A}, \mathrm{n}$ are constants. For a relay current $\mathrm{I}$ exceeding the pickup value Ip, relay operating time $(\mathrm{t})$ is equal to the period elapsed since the occurrence of abnormal condition until relay trip-ping.

\section{B. Over-voltage (or voltage swell) protection}

For over-voltage protection, the proposed MNR is designed to have inverse time-voltage characteristics because most of the dam-age caused by overvoltage due to overheating [17]. The inverse characteristic for overvoltage is defined [17] by Eq. (2):

$$
\left|\frac{V}{V_{s}}-1\right| t=T M S
$$

where $\mathrm{V}$ is the system voltage, Vs is the relay setting voltage which lies in a range of voltage around the rated value, TMS is time multiplier setting and $t$ is the time duration of the over-voltage(or voltage swell), after it the relay trips the circuit breaker to dis-connect the overvoltage section (See Fig. 4)

\section{Under-voltage (or voltage sag) protection}

The principle of operation of the proposed MNR in case of under-voltage is based on the inverse characteristic for under-voltage. The inverse characteristic for overvoltage, is defined [17] by Eq.(2). The operating principle of the undervoltage relay follows the same manner as that of the overvoltage relay but with opposite logic.

\section{Over- and under frequency protection}

The proposed MNR is designed to trip the circuit breaker in case the system frequency deviates significantly from the nominal value. With the frequency deviation, the relay has the capability to shed some system load in order to bring the frequency close to nominal value, thus, keeping the continuity of supply. In case of $50 \mathrm{~Hz}$, ithas been reported [9] that load shedding is $33 \%$ of the load if the magnitude of the frequency deviation $|\mathrm{f}|$ exceeds $0.5 \mathrm{~Hz}, 66 \%$ of the load if $\left|\_f\right|$ exceeds $1 \mathrm{~Hz}$ and all the load if $|\mathrm{f}|$ exceeds $1.5 \mathrm{~Hz}$. To avoid working under transient conditions, the relay operation is delayed some time_t (5 s [8]) before shedding any part of the load. This time delay can be adjusted to any value. 
International Journal of Innovative Research in Electrical, Electronics, Instrumentation and Control Engineering

Vol. 9, Issue 3, March 2021

\section{DOI 10.17148/IJIREEICE.2021.9301}

\section{Over temperature protection}

Winding temperature indicates the hottest portion in transformer winding. Winding temperature decides the loading capability of transformer. Winding temperature sensors are fixed in the transformer which are helpful in assessing transformer's life. Here, temperature sensor used is $\mathrm{LM} 35$, as its temperature range is between $-55^{\circ} \mathrm{C}$ to $150^{\circ} \mathrm{C}$ and as per literature [4], winding temperature can rise above $60^{\circ} \mathrm{C}$.

\section{EXPERIMENTAL RESUlts}

The experimental setup is illustrated in Fig. 5. This figure contains hardware setup for IoT based system, which includes whole circuitry, Internet modem fitted with 3G modem and Arduino Microcontroller. This work develops a monitoring system via an Ethernet LAN on the intended substation, the in-built system by monitoring the zero crossing of current and voltage during low voltage and over voltage, fault protection, fault detection and fault prevention. This helps the utility from unnecessary power outages, and increases the life time of the transformer and increase the service time. The system also provides an online control of the distribution transformer remotely via Internet of Things technology, and it helps the customer to avoid frequent power failures and ensure reliable and good quality power being supplied to the consumers.

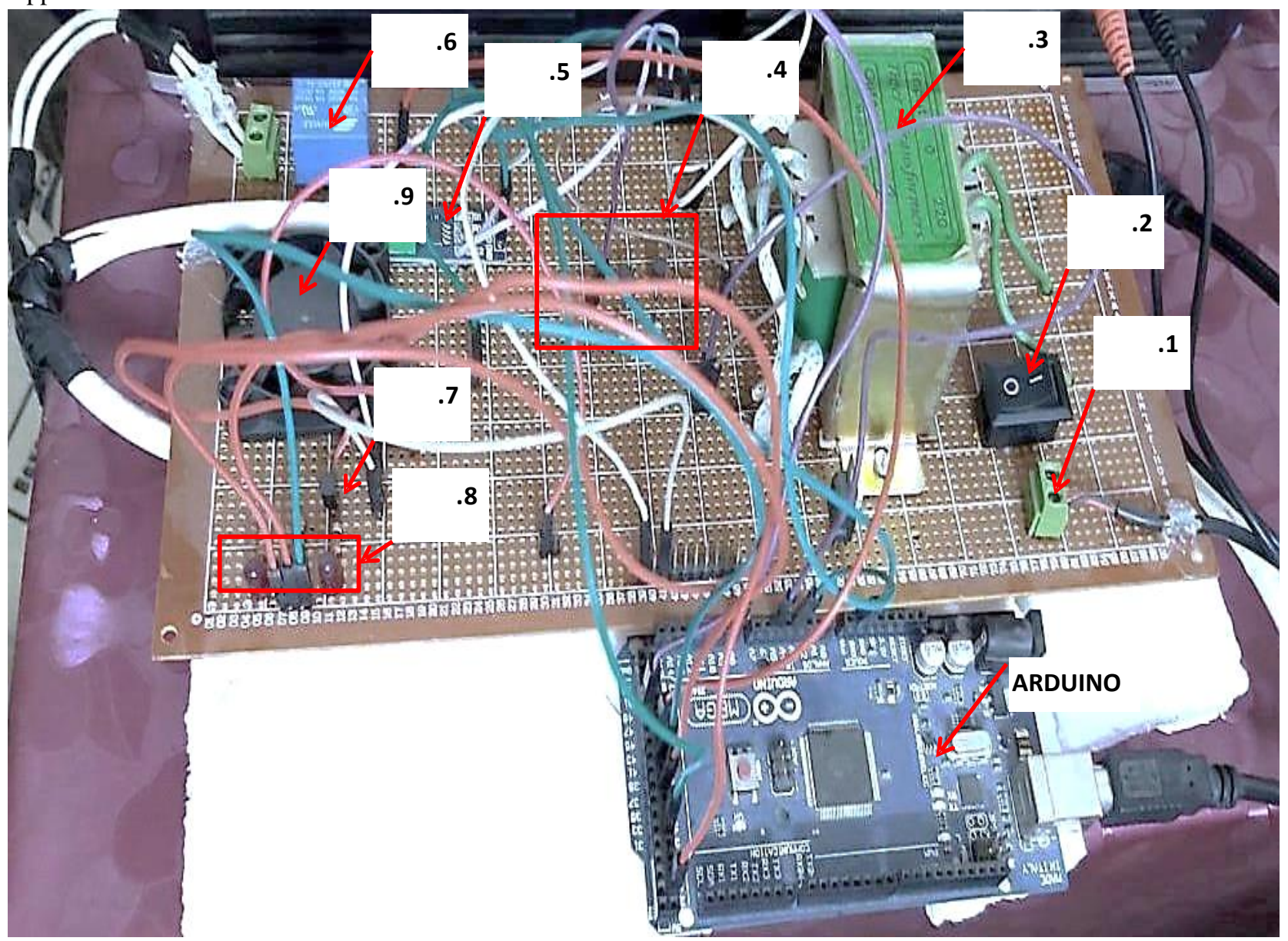

Fig. 5 The whole electronic circuit and ARDUINO

1. Input DC power.

3. A decreasing-voltage transformer.

5. A current sensor.

7. LM35 temperature sensor.
2. ON/OFF switch.

4. A transistor-as-switch circuit.

6. Output relay.

8. Output LEDs. 9. DC fan. 


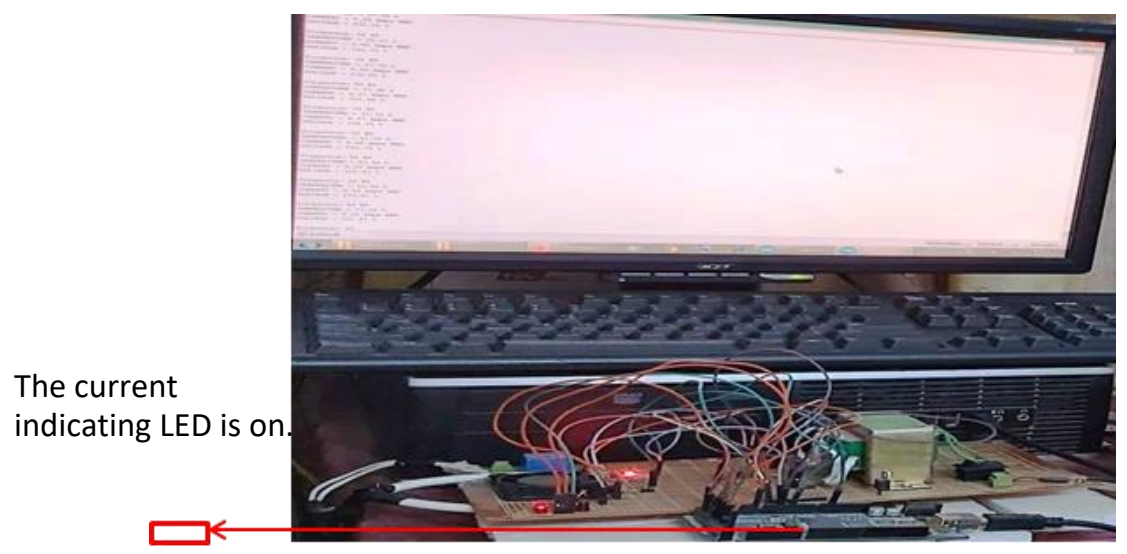

Fig. 6 The whole circuit with load connected to it.

The problems of the Arduino Programming Department while working on it experimentally:

1. Time to sample the analog signal for voltage and current measurement By trying, we found that it's more accurate to take the sample for $\mathrm{X}$ mille-seconds or more.

2. Noise during measuring frequency. During the frequency measurement process, we found that the frequency values were changing randomly, because of electrical noise. So we performed two configurations to overcome this problem.

3. The input pin, which is used to receive the frequency signal, is connected to a pull-up resistor; this way is used to connect the pin to the positive voltage $(+\mathrm{Vcc})$ through a resistor, and hence eliminates noise on this pin.

4. Disabling the global interrupt to prevent noise from interrupting the processor after finishing recording the readings.

5. Using interrupt instead of polling.

6. In ARDUINO coding, polling is a process of waiting for the incoming signal to be received then dealing with it; but, interrupt is a process of not waiting for the signal, or, in other words, the processor continues running code instructions but when the incoming signal is received it fires an interrupt for the processor to stop running the main code and turns to the ISR (Interrupt Service Routine) to be run, and inside this ISR function we deal with the incoming signal. So we used interrupt, because it saves processor time more than polling does.

Figure 7 indicated the reading taken from Aruino microcontroller to the PC. Several reading are taken for temperature, current, voltage and frequency. We introduced a time delay after printing values on computer screen, so that we can completely read values. In other words, values are being updated on computer screen every one or two seconds.

Using timer to measure the frequency instead of ADC, and because the timer input must be digital, so we had to convert the analog signal into a digital one. That's the reason why we used Timer instead of the ADC, because digital signal is less to be affected by noise than analog signal does. Also, the ADC has a limitation on frequency that it can't measure frequencies above $15 \mathrm{KHZ}$ (from datasheet the ADC conversion takes 13 ADC clock cycle on maximum frequency of $200 \mathrm{KHZ}$ ).

To turn on the fan we had to connect it to a voltage of 12 volt dc, but the output voltage from the ARDUINO has a maximum voltage of 5 volt only. So we used a transistor as a switch circuit to drive the fan by using the 5 volt ARDUINO signal.

All the voltages needed in our circuit are 5 voltages except for the fan which need a voltage of 12 volt, so we used the regulator (2805) to convert voltage from 12 down to 5 volts. At first, we kept the negative portion of the AC signal as it would be eliminated by the transistors and ignored by the ARDUINO, but we found that the ground wasn't stable. So we put a DIODE to eliminate the negative portion and after that the ground has been stabilized.

We used a digital pin number 5 to turn on a LED indicating any change in frequency. At first, this pin showed unpredictable behavior because it is connected to another function associated with the serial communication inside the ARDUINO board. So we had to connect the LED on another pin. [12] 
International Journal of Innovative Research in Electrical, Electronics, Instrumentation and Control Engineering

Vol. 9, Issue 3, March 2021

DOI 10.17148/IJIREEICE.2021.9301

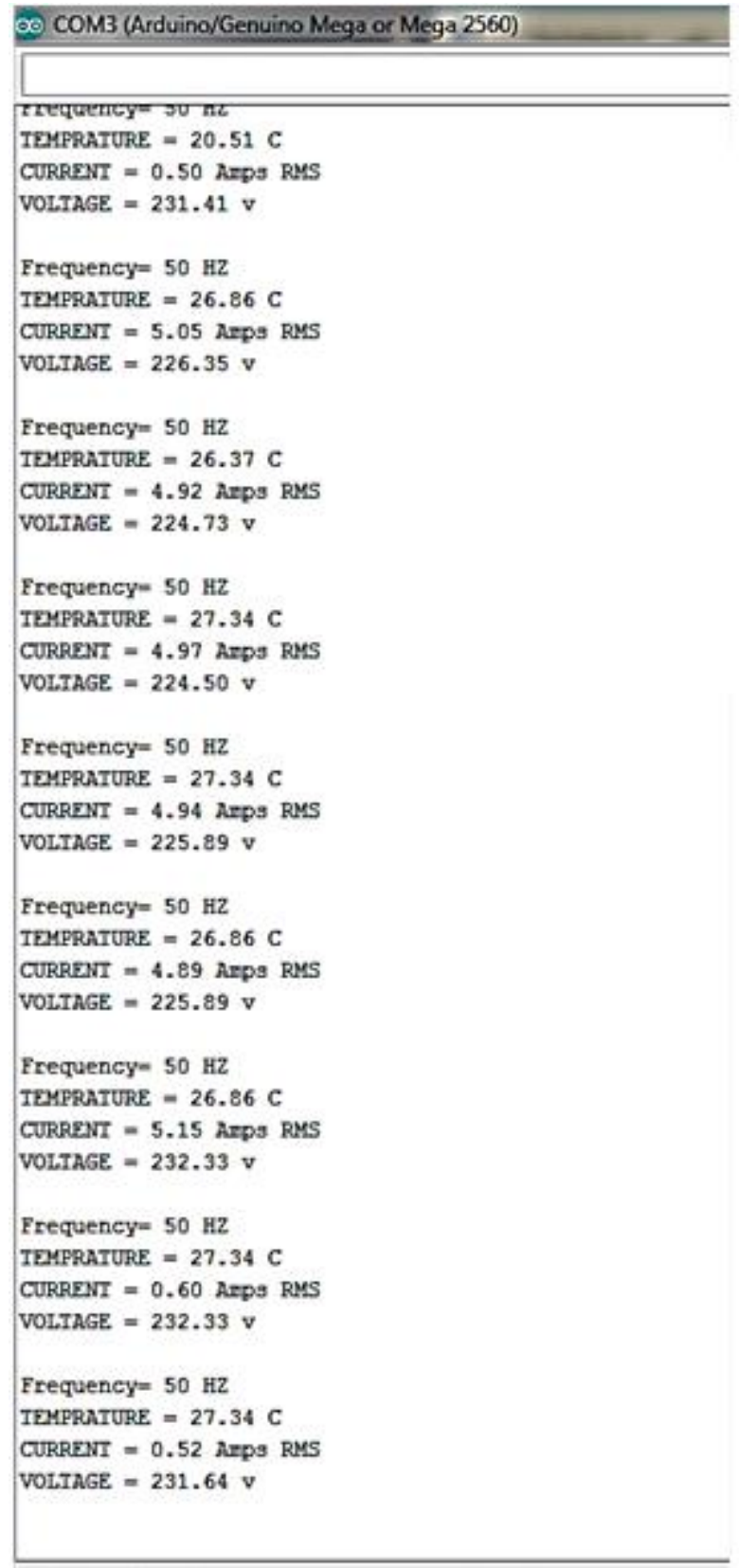

Fig. 7 Arduino readings with and without load

\section{VI.CONCLUSION}

This systems aims to protect transformers from overloading and overheating faults which may damage the transformer The system succeeded in disconnecting the loads in case of overloading faults and running the cooling system in case of overheating faults. Also, the system enables us from monitoring temperature, voltage, current and frequency values on real time through a computer connection. The system has indicating LEDs to help in faults maintenance. The IOT based solution for monitoring and controlling of distribution transformers is quite easy and effective compared to manual monitoring method. Reliable power distribution system must use protective devices which will essentially reduce running cost. Continuous monitoring of Distribution transformer, timely alerts to rectify the abnormality if any, there by extending the lifetime of distribution transformers This study will help in cost minimization by reducing the workforce in maintenance. And real-time load monitoring and control will improve system efficiency. 
International Journal of Innovative Research in Electrical, Electronics, Instrumentation and Control Engineering

Vol. 9, Issue 3, March 2021

\section{DOI 10.17148/IJIREEICE.2021.9301}

\section{REFERENCES}

[1] Khairy Sayed, Farid Naguib Abdelbar, Emad Elzohri, Allam Ahmed, "Monitoring and Rationalizing Energy Consumption of Home Electric Appliances", International Journal of Innovative Research in Electrical, Electronics, Instrumentation and Control Engineering, Vol. 8, Issue 11, November 2020, DOI 10.17148/IJIREEICE.2020.81101J

[2] T. A. Kumar and A. Ajitha, "Development of IOT based solution for monitoring and controlling of distribution transformers," 2017 International Conference on Intelligent Computing, Instrumentation and Control Technologies (ICICICT), Kannur, 2017, pp. 1457-1461, doi: 10.1109/ICICICT1.2017.8342784

[3] T. K. Roy and T. K. Roy, "Implementation of IoT: Smart Maintenance for Distribution Transformer using MQTT," 2018 International Conference on Computer, Communication, Chemical, Material and Electronic Engineering (IC4ME2), Rajshahi, 2018, pp. 1-4, doi: 10.1109/IC4ME2.2018.8465489.

[4] S. Zhang, C. Zhu, J. K. O. Sin, and P. K. T. Mok, "A novel ultrathin elevated channel low-temperature poly-Si TFT," IEEE Electron Device Lett., vol. 20, pp. 569-571, Nov. 1999.

[5] K. Surendra and C. Vyjayanthi, "Short Circuit Studies on a Distribution System Integrated with Various Distributed Generations," 2018 IEEE 8th Power India International Conference (PIICON), Kurukshetra, India, 2018, pp. 1-6, doi: 10.1109/POWERI.2018.8704410.

[6] Y. Tang and R. Ayyanar, "Methodology of Automated Protection Analysis for Large Distribution Feeders With High Penetration of Photovoltaic Systems," in IEEE Power and Energy Technology Systems Journal, vol. 4, no. 1, pp. 1-9, March 2017, doi: 10.1109/JPETS.2016.2578942.

[7] M. A. Awadallah, T. Xu, B. Venkatesh and B. N. Singh, "On the Effects of Solar Panels on Distribution Transformers," in IEEE Transactions on Power Delivery, vol. 31, no. 3, pp. 1176-1185, June 2016, doi: 10.1109/TPWRD.2015.2443715.

[8] Humberto Jimenez, Hugo Calleja, Raul Gonzalez Galarza and Javier Lagunas, "The impact of photovoltaic systems on distribution transformer: A case study", March 2006, Energy Conversion and Management 47(4):311-321, DOI: 10.1016/j.enconman.2005.04.007 M. A. Awadallah, T. Xu, B. Venkatesh and B. N. Singh, "On the Effects of Solar Panels on Distribution Transformers," in IEEE Transactions on Power Delivery, vol. 31, no. 3, pp. 1176-1185, June 2016, doi: 10.1109/TPWRD.2015.2443715.

[9] S. Taheri, H. Taheri, I. Fofana, H. Hemmatjou, and A. Gholami, "Effect of power system harmonics on transformer loading capability and hot spot temperature," In Proc. IEEE Canadian Conference on Electrical and Computer Engineering, April 29 - May 2, 2012 , Montreal, QC, Canada, pp. 1-4.

[10] Khairy Sayed, Mazen Abdel-salam, Adel Ahmed, Mahmoud Ahmed, "A ripple current minimisation based single phase PWM inverter", Int. Journal of Power Electronics, Vol. 6, No. 3, pp. 201-223, 2014

[11] M. S. Dalila, M. N. Khalid, and M. Md. Shah, "Distribution transformer losses evaluation under non-linear load," In Proc. Australian Universities Power Engineering Conference, September 27-30, 2009, Adelaide, Australia, pp. 1-6.

[12] P. S. Moses, M. A. S. Masoum, and K. M. Smedley, "Harmonic losses and stresses of nonlinear three-phase distribution transformers serving plug-in electric vehicle charging stations," In Proc. IEEE-PES Conference on Innovative Smart Grid Technologies, January 17-19, 2011, Anaheim, CA, USA, pp. 1-6.

[13] S. Ram, J. A. C. Forrest, and G. W. Swift, "Effects of harmonics on converter transformer load losses," IEEE Trans. on Power Delivery, Vol. 3, No. 3, 1988, pp. 1059-1066.

[14] Y. Han and Y.-F. Liu, “A practical transformer core loss measurement scheme for high-frequency power converter," IEEE Trans. On Industrial Electronics, Vol. 55, No. 2, February 2008, pp. 941-948.

[15] Mazen Abdel-Salam, Khairy Sayed, Adel Ahmed, Mahmoud Amery, Mohamed Swify", Design, Implementation and Operation of a Standalone Residential Photovoltaic System ", Int. J. Power and Energy Conversion, Vol. 8, No. 1, pp. 47-67, 2017.

[16] M. A. Awadallah, B. Venkatesh, and B. N. Singh, "Impact of solar panels on power quality of distribution networks and transformers," IEEE Canadian Journal of Electrical and Computer Engineering, vol. 36, no. 1, 2015, pp. 45-51.

[17] Mazen Abdel-Salam, Rashad Kame, Khairy Sayed, Mohsen Khalaf, "Design and implementation of a multifunction DSP-based-numerical relay", Electric Power Systems Research 143 (2017) 32-43.

[18] C. J. Chou and W. P. Hong, "Real time distributed generation monitoring at substation based on feeder IED functions and load profiles," 2018 7th International Symposium on Next Generation Electronics (ISNE), Taipei, 2018, pp. 1-3, doi: 10.1109/ISNE.2018.8394632.

[19] Xiaowei Wang, Jun Gao, Wenping Hu, Zhengang shi and Baofeng Tang, "Research of effect on distribution network with penetration of photovoltaic system," 45th International Universities Power Engineering Conference UPEC2010, Cardiff, Wales, 2010, pp. 1-4.

[20] H. Ravindra, M. O. Faruque, P. McLaren, K. Schoder, M. Steurer and R. Meeker, "Impact of PV on distribution protection system," 2012 North American Power Symposium (NAPS), Champaign, IL, 2012, pp. 1-6, doi: 10.1109/NAPS.2012.6336409.

[21] E. Kim and D. Kim, "Performance testing of Grid-connected photovoltaic inverter based on an integrated electronic protection device," 2009 Transmission \& Distribution Conference \& Exposition: Asia and Pacific, Seoul, 2009, pp. 1-4, doi: 10.1109/TD-ASIA.2009.5356868.

[22] S. Hashemi and J. Østergaard, "Methods and strategies for overvoltage prevention in low voltage distribution systems with PV," in IET Renewable Power Generation, vol. 11, no. 2, pp. 205-214, 82 2017, doi: 10.1049/iet-rpg.2016.0277.

[23] Naveed Ashraf, Tahir Izhar, Ghulam Abbas ,Ahmed Bilal Awan ,Ali S Alghamdi and Khairy Sayed, "New Single-Phase Direct Frequency Controller Having Reduced Switching Count without Zero-Crossing Detector for Induction Heating System", Electronics 2020, 9(3), 430; https://doi.org/10.3390/electronics9030430 - 9 (3

[24] Praveen R.P. ; Jose Therattil ; Jenson Jose ; Ahmed Abo-Khalil ; Ali Alghamdi ; G.R Bindu ; Khairy Sayed, "Hybrid Control of a Multi Area Multi Machine Power System with FACTS Devices using Non-linear Modelling", IET Generation, Transmission \& Distribution, Vol. 14 , No. 10 , pp. 1993 - 2003, 2020.

[25] Hedra Saleeb, Khairy Sayed, Ahmed Kassem, Ramadan Mostafa, Control and analysis of bidirectional interleaved hybrid converter with coupled inductors for electric vehicle applications", Electrical Engineering, pp. 1-28, 2019.

[26] Khairy Sayed, Ahmed G. Abo-Khalil, and Ali S. Alghamdi, "Optimum Resilient Operation and Control DC Microgrid Based Electric Vehicles Charging Station Powered by Renewable Energy Sources", Energies 2019, 12, 4240; doi:10.3390/en12224240

[27] Khairy Sayed and Hossam Gabbar, "Smart Distribution System Volt/VAR Control Using the Intelligence of Smart Transformer", Proceedings of the 4th IEEE International Conference on Smart Energy Grid Engineering SEGE 2016, pp. 52-56.

[28] Sayed, K., Abo-Khalil, A.G., Eltamaly, A.M., " Wind Power Plants Control Systems Based on SCADA System",Book Chapter, Green Energy and Technology, 2021, pp. 109-151.

[29] K Sayed, HA Gabbar, "SCADA and smart energy grid control automation", book chapter, Smart Energy Grid Engineering, 481-514, 2016.

[30] K. Sayed, M. Abdel-Salam, M. Ahmed, A. Ahmed, "Modeling and simulation of PV arrays", ASME International Mechanical Engineering Congress and Exposition, IMECE2010-38969, pp:1-8, Vancouver, British Columbia, Canada, November 12-18, 2010. 